\title{
PENGEMBANGAN ALAT UKUR VISKOSITAS AIR SUNGAI TERCEMAR LIMBAH CAIR BERBASIS SENSOR OPTIK TIPE THROUGH BEAM
}

\author{
Leni Andayani ${ }^{\text {a) }}$, Widyaningrum Indrasari ${ }^{\text {b) }}$, Umiatin ${ }^{\text {c) }}$ \\ Program Studi Fisika Fakultas Matematika dan Ilmu Pengetahuan Alam Universitas Negeri Jakarta, Jl. \\ Rawamangun Muka, Jakarta 13220
}

Email: ${ }^{a}$ leniandayani7991@gmail.com, ${ }^{\text {b) }}$ widyafisikaunj@gmail.com, ${ }^{\mathrm{c})}$ ummiatin@yahoo.com

\begin{abstract}
Abstrak
Dewasa ini ketersediaan air bersih semakin menurun, tidak sebanding dengan kebutuhan air bersih yang kian meningkat. Banyaknya penduduk dan peningkatan industri mengakibatkan produksi limbah cair semakin banyak. Kualitas air yang baik ditentukan berdasarkan beberapa parameter fisis antara lain suhu, kekeruhan, warna, daya hantar listrik, jumlah zat padat terlarut, salinitas, indeks bias, tegangan permukaan, $\mathrm{pH}$ dan viskositas. Viskositas merupakan indikator yang penting dalam menentukan kualitas air tercemar, namun alat ukur viskositas sangat terbatas. Oleh karena itu diperlukan pembuatan alat ukur viskositas yang efektif, efisien dan presisi. Pada penelitian ini telah dikembangkan alat ukur viskositas zat cair yang memanfaatkan sensor optik tipe through beam berbasis Arduino Uno R3. Dari hasil karakterisasi sensor viskositas menggunakan viskometer Ostwald diperoleh sensitivitas sensor sebesar $17.31 \mathrm{mV} / \mathrm{cP}$ dengan kesalahan relatif maksimum 4.605\%. Hasil pengukuran sampel air sungai ( Banjir Kanal Timur (BKT), Bekasi, Cipinang dan Galur ) diperoleh nilai viskositas berturut-turut $1.246 \mathrm{cP}, 1.268 \mathrm{cP}, 1.248 \mathrm{cP}$ dan $1.546 \mathrm{cP}$. Hasil pengukuran sampel air sungai menunjukkan bahwa nilai viskositas air sungai tersebut melebihi batas normal air bersih yaitu $1.002 \mathrm{cP}$ pada suhu $20^{\circ} \mathrm{C}$, sehingga air sungai di atas dapat dikatakan tercemar.
\end{abstract}

Kata-kata kunci : Viskositas, sensor viskositas, sensor optik.

\begin{abstract}
Today, the availability of clean water is decreasing, not worth the need for a growing water. Many population and industry improvement resulted in more liquid waste production. Good water quality is determined based on several parameters phisycs among others temperature, turbidity, color, electrical power, the amount of dissolved solids, salinity, refractive index, surface tension, $\mathrm{pH}$ and viscosity. Viscosity is an important indicator in determining the quality of polluted water, but the viscosity measuring instrument is very limited. It is therefore necessary to manufacture effective, efficient and precise viscosity measuring instruments. In this study, a liquid measuring instrument has been developed that utilizes the Arduino Uno R3-based through beam type optical sensor. From the results of characterization of viscosity sensors using the Ostwald viscometer obtained sensor sensitivity of $17.31 \mathrm{mV} / \mathrm{cP}$ with a maximum relative error of $4,605 \%$. The results of river water sampling (East Canal Flood (BKT), Bekasi, Cipinang and Galur) were obtained in successive viscosity values of $1,246 \mathrm{cP}, 1,268 \mathrm{cP}, 1,248 \mathrm{cP}$ and $1,546 \mathrm{cP}$. The results of the river water sample measurement showed that the viscosity of the river water value exceeded the normal clean water limit of $1,002 \mathrm{cP}$ at $200 \mathrm{C}$, so the river water above can be said to be polluted.
\end{abstract}

Keywords: viscosity, viscosity sensor, optical sensor. 


\section{PENDAHULUAN}

Kebutuhan air bersih merupakah kebutuhan yang sangat penting bagi makhluk hidup terutama manusia. Dengan meningkatnya jumlah penduduk dan jumlah industri maka kebutuhan air sesuai peruntukannya semakin meningkat pula, tetapi tingkat kualitas air semakin menurun dari hari ke hari akibat tercemar limbah. Kualitas air diantaranya ditentukan oleh parameter fisika berikut, yakni suhu, kekeruhan, warna, daya hantar listrik, jumlah zat padat terlarut, salinitas, indeks bias, tegangan permukaan, $\mathrm{pH}$ dan viskositas [1].

Parameter fisika yang cukup penting adalah nilai viskositas zat cair. Viskositas merupakan ukuran yang menyatakan kekentalan suatu cairan uji. Kekentalan tak lain adalah sifat cairan yang sangat erat kaitannnya dengan hambatan dari suatu cairan uji yang mengalir [2]. Dibidang instrumentasi saat ini sudah terdapat alat yang digunakan untuk mengukur tingkat kualitas air berdasarkan parameter viskositas. Viskometer merupakan alat yang digunakan untuk menentukan nilai viskositas fluida.. Pada penelitian sebelumnya telah dibuat alat ukur viskositas yang memanfaatkan sensor efek hall dengan metode bola jatuh oleh Tissos, namun pada penelitian ini terbatas hanya bola pejal berdiameter kecil saja yang bisa dilewatkan karena sensitivitas yang kurang baik [3].

Saat ini alat uji kualitas viskositas sangat terbatas, hal ini menyebabkan kurang efisien untuk mengetahui kualitas air dari parameter viskositas. Oleh sebab itu perlu dikembangkan sutu alat deteksi viskositas zat cair yang efisien dan efektif.

Sistem untuk mendeteksi nilai viskositas zat cair pada penelitian ini memanfaatkan sensor optik tipe through beam. Sensor through beam memiliki elemen sumber dan detektor cahaya yang terpisah dan disusun sejajar saling berhadapan, dengan sorotan cahaya memotong jalur yang akan dilewati oleh objek. Area sorotan efektif adalah kolom dimana cahaya melintas lurus diantara lensa-lensa. Prinsip kerja through beam adalah pada saat tidak ada objek yang melintas diantara sumber dan detektor, cahaya dari sumber diterima oleh detektor. Jika ada objek melintas, cahaya dari sumber terhalang sehingga tidak diterima oleh detektor aki, dengan demikian penyaklaran dan keluaran terjadi [4].

Sensor photodiode merupakan bagian penting dari sensor optik ini. Sensor photodiode merupakan sensor yang peka terhadap cahaya (photo detector), dimana sensor ini akan mengalami perubahan arus jika menerima intensitas cahaya. Perubahan arus ini lah yang menyebabkan adanya perubahan resistansi pada sensor sehingga terdapatnya perubahan tegangan keluaran pada sensor [5].

Untuk mengetahui tingkat akurasi dari sensor yang digunakan, maka dilakukan karakterisasi dengan membandingkan nilai tegangan keluaran sensor dengan alat uji yang sudah ada pada laboratorium dalam hal ini menggunakan viskometer Ostwald, yang dijadikan sebagai acuan dalam membuat sistem ini.

\section{METODE PENELITIAN}

Metode penelitian yang digunakan pada penelitian ini adalah ekperimen dengan mengembangkan deteksi kualitas air berdasarkan parameter viskositas berbasis Arduino yang memanfaatkan sensor optik tipe through beam. Sensor tipe ini menggunakan photodioda sebagai receiver dan LED merah sebagai transmitter. Prinsip kerjanya yaitu dengan melewatkan larutan diantara receiver dan transmitter.

Pengambilan data dilakukan dengan menggunakan 10 sampel larutan air aquades dengan penambahan konsentrasi detergen cair yang bervariasi yaitu pada rentang $0 \%-0.9 \%$. 


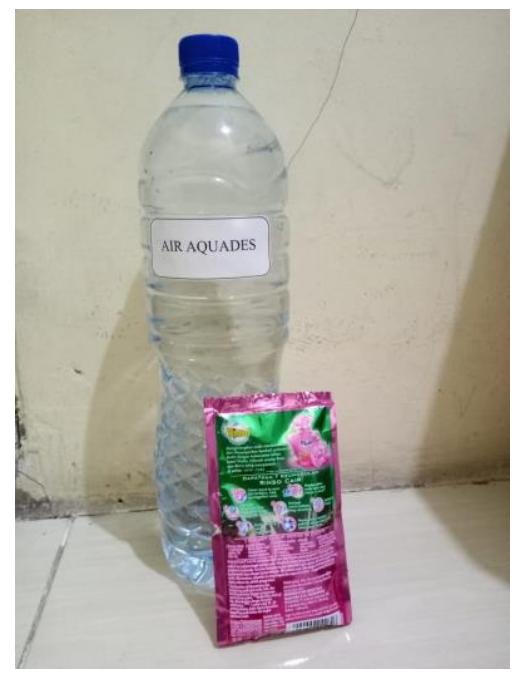

(a)

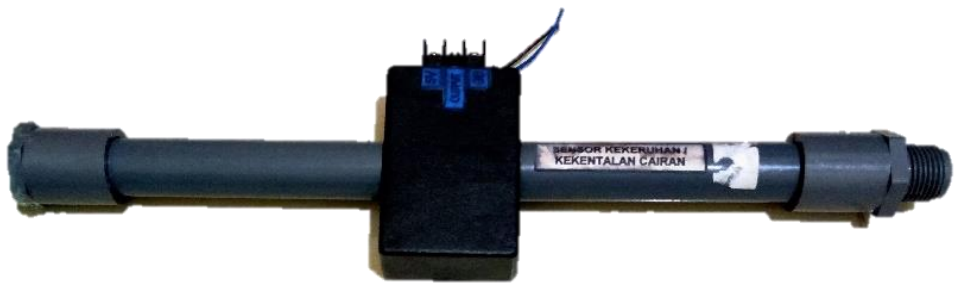

(b)

GAMBAR 1. a). Sampel larutan untuk kalibrasi, b) Sensor Viskositas

GAMBAR 1.a) merupakan sampel larutan yang digunakan untuk kalibrasi, terdiri atas aquades sebanyak 1 liter dan detergen cair yang digunakan sebagai pengotor pada larutan aquades sedangkan GAMBAR 1.b) merupakan gambar sensor viskositas untuk mengukur kekentalan suatu zat cair yang akan diuji.

Sensor yang digunakan saat kalibrasi adalah sensor viskositas yang memanfaatkan sensor optik tipe trough beam dapat dilihat pada gambar 1.b). Sensor tersebut terintegrasi dengan mikrokontroller dan LCD 16x2. Hasil dari pengukuran sensor ini ditampilkan pada layar LCD 16x2. Besar kesalahan relatif sensor dapat dihitung dengan menggunakan persamaan berikut [6].

$$
\operatorname{Error}(\%)=\frac{|P S-P L|}{P L} \times 100 \%
$$

Dengan PS adalah pembacaan nilai viskositas keluaran pada sensor yang digunakan, dan PL adalah pembacaan nilai viskositas yang diuji menggunakan alat laboratorium.

\section{HASIL DAN PEMBAHASAN}

\section{Karakterisasi Sensor Viskositas}

Pada karakterisasi sensor viskositas zat cair yang memanfaatkan sensor optik tipe through beam dilakukan dengan membandingkan nilai keluaran sensor dengan hasil alat ukur di laboratorium. Pada penelitian ini menggunakan viskometer Ostwald sebagai pembanding saat kalibrasi. Nilai digital keluaran sensor memiliki satuan miliVolt $(\mathrm{mV})$ dan nilai hasil pengukuran laboratorium dengan viskometer Ostwald memiiki satuan centiPoise (cP). Hasil Pengukuran terdapat pada TABEL 1.

TABEL 1. Data nilai viskositas laboratorium dan viskositas sensor

\begin{tabular}{clccc} 
No & Sampel & $\begin{array}{c}\text { Hasil Pengukuran } \\
\text { LAB (cP) }\end{array}$ & $\begin{array}{c}\text { Hasil Pengukuran } \\
\text { Sensor Viskositas(cP) }\end{array}$ & $\begin{array}{c}\text { Kesalahan } \\
\text { Relatif (\%) }\end{array}$ \\
\hline 1 & Aquades 1 liter + 0\% Detergen Cair & 1.002 & 1.048 & 4.605 \\
2 & Aquades 1 liter + 0.1\% Detergen Cair & 1.416 & 1.406 & 0.652 \\
3 & Aquades 1 liter + 0.2\% Detergen Cair & 1.712 & 1.635 & 4.473 \\
4 & Aquades 1 liter + 0.3\% Detergen Cair & 1.915 & 1.937 & 1.116
\end{tabular}


Kesalahan relatif pengukuran oleh sensor dihitung menggunakan persamaan (1) sehingga diperoleh grafik pada GAMBAR 2.

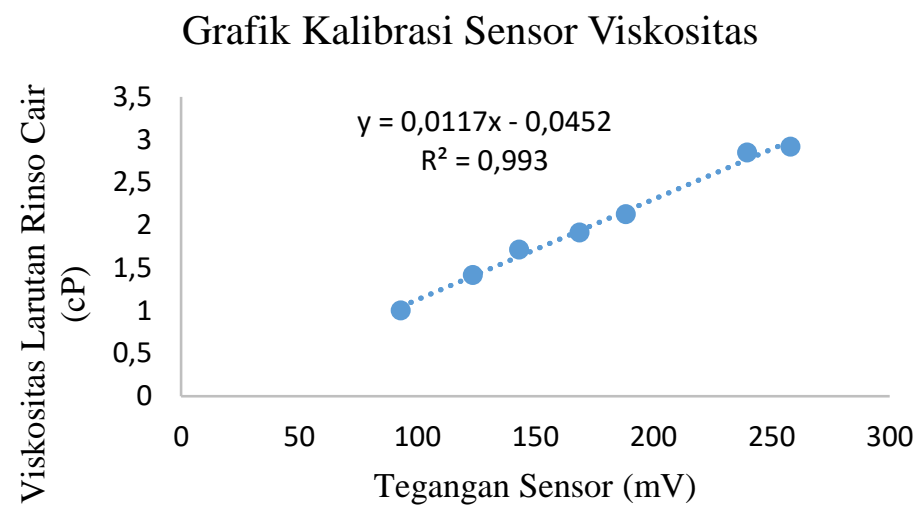

GAMBAR 2. Grafik hubungan tegangan keluaran sensor terhadap hasil uji viskositas di laboratorium

Berdasarkan grafik di atas, didapat persamaan invers fungsi transfer sebagai berikut:

$$
y=17.31 x+1.0294
$$

Dengan y merupakan nilai dari perubahan tegangan yang dihasilkan sensor viskositas dalam satuan miliVolt $(\mathrm{mV})$ dan $\mathrm{x}$ merupakan nilai viskositas yang terbaca oleh sensor dengan satuan centipoise (cP). Grafik pada GAMBAR 2 menunjukkan bahwa nilai tegangan keluaran berbanding lurus terhadap besaran viskositas yang terukur. Hal ini menandakan bahwa semakin besar nilai viskosittas maka akan semakin besar pula nilai tegangan keluarannnya. Hal ini dikarenakan resistansi yang dihasilkan oleh photodiode sebagai sensor optik semakin besar. Semakin besarnya nilai viskositas yang dihasilkan mengindikasikan semakin kentalnya suatu zat cair. Berdasarkan hasil pengukuran diperoleh nilai kesalahan relatif maksimum yang terdapat pada sampel no 1 yaitu sebesar $4.605 \%$. Sensitivitas sensor viskositas yang diperoleh sebesar $17.31 \mathrm{mV} / \mathrm{cP}$, yang artinya setiap perubahan 1 centiPoise akan menghasilkan tegangan keluaran sebesar $17.31 \mathrm{mV}$. Sensor viskositas ini bekerja dengan baik pada rentang $1.048 \mathrm{cP}-2.98 \mathrm{cP}$.

\section{Pengujian Sampel}

Pengujian sistem pengkuran viskositas dilakukan pada bulan Mei-Juni 2017. Pengujian dilakukan dengan pembacaan sensor viskositas. Digunakan empat sampel air sungai yang telah dilakukan uji viskositas dengan volume air masing-masing 1 Liter. 


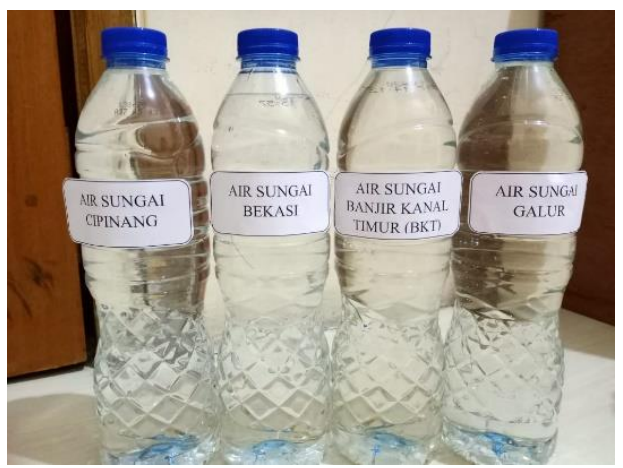

GAMBAR 3. Sampel larutan uji

GAMBAR 3 menunjukan empat sampel air sungai yang telah diukur nilai viskositasnya, adapun hasil pengukuran nilai viskositas sampel air sungai tersebut oleh sensor dirangukum pada TABEL 2.

TABEL 2. Daftar sampel larutan uji

\begin{tabular}{|c|c|c|}
\hline No & Sampel yang di Uji & Viskositas Terukur Sensor (cP) \\
\hline 1 & 1 Liter Air Sungai Banjir Kanal Timur (BKT) & 1.246 \\
\hline 2 & 1 Liter Air Sungai Bekasi & 1.269 \\
\hline 3 & 1 Liter Air Sungai Cipinang & 1.428 \\
\hline 4 & 1 Liter Air Sungai Galur Jakarta Pusat & 1.546 \\
\hline
\end{tabular}

Dari hasil pengujian keempat jenis larutan di atas, dapat diketahui nilai viskositas tertinggi terdapat pada larutan ke 4 yaitu air sungai Galur, Jakarta Pusat yaitu sebesar $1.546 \mathrm{cP}$. Artinya air sungai Galur ini dapat dikatakan sebagai air tercemar, karena air bersih layak konsumsi pada suhu $20^{\circ} \mathrm{C}$ adalah $1.002 \mathrm{cP}$ [7]. Air sungai Galur, Jakarta Pusat juga paling tercemar di antara air sungai yang diuji lainnya. Hal ini dapat terlihat pula dari segi warna air sungai galur lebih pekat dari yang lainnya hal diakibatkan oleh pembuangan limbah rumah tangga penduduk sekitar sungai yang cukup padat.

\section{SIMPULAN}

Karakterisasi sensor telah dilakukan menggunakan mikrokontroller Arduino uno, didapatkan bahwa bahwa sensor viskositas ini bekerja dengan baik pada rentang $1.048 \mathrm{cP}-2.98 \mathrm{Cp}$ serta memiliki niai sensitivitas sebesar $17.31 \mathrm{mV} / \mathrm{cP}$ dan kesalahan relatif maksimum sebesar 4.605\%. Dengan demikian sensor ini dapat digunakan untuk mendeteksi viskositas dengan cukup presisi dan dapat digunakan untuk menentukan apakah sampel yang di uji tercemar atau tidak.

\section{REFERENSI}

[1] H. Effendi, Telaah Kualitas Air Bagi Pengelolaan Sumber Daya dan Lingkungan Perairan, Yogyakarta: Kanisius, 2003.

[2] E. Yazid, Kimia Fisika untuk Paramedis, Yogyakarta: Penerbit Andi, 2005.

[3] N. Tissos dkk., "Pembuatan Sistem Pengukuran Viskositas Fluida Secara Digital Menggunakan Sensor Efek Hall UGN3503 Berbasis Arduino UNO328," in Jurnal Saintek, Vol. VI, No. 1, 2014, pp. 71-83.

[4] A. Priyanto, Prototipe Mesin Pemilahan Barang Sesuai Jenisnya. Yogyakarta: Universitas Sanata Dharma, 2015.

[5] D. Wulandari dkk., 2014, "Studi Awal Rancang Bangun Colorimeter Sebagai Pendeteksi Pada Pewarna Makanan Menggunakan Sensor Photodioda," in Pillar of Physics, Vol. 11, No. 2, 2018, pp. 81-87.

[6] J. Fraden, Handbook of Modern Sensor: Physics, Designs, and Applications, California: Advanced Monitors Corporation, 2003. 
[7] R. A. Serway, Physics for Scientists \& Engineers $4^{\text {th }}$ Edition, Saunders College Publishing, 1996. 